Original Research Paper

\title{
The Extent of Smartphones Users to Adopt the Use of Cloud Storage
}

\author{
${ }^{1}$ Khaled Aldiabat, ${ }^{2}$ Ameer Sardar Kwekha Rashid, ${ }^{3}$ Hind Talafha and ${ }^{4}$ Ahmad Karajeh \\ ${ }^{I}$ Management Information System, Ajloun National University, Jordan \\ ${ }^{2}$ Department of Marketing Management, University of Sulaimani, Iraq \\ ${ }^{3}$ Department of Computer Information System, Researcher, Jordan \\ ${ }^{4}$ Department of Accounting, Ajloun National University, Jordan
}

Article history

Received: 13-11-2018

Revised: 29-11-2018

Accepted: 06-12-2018

Corresponding Author:

Khaled Aldiabat

Management Information

System, Ajloun National

University, Jordan

Email:khaledmis@yahoo.com

\begin{abstract}
Recently, technology has witnessed a rapid progress and dominates all aspects of life systematically. Smartphones are devices that users can depend on managing and storing data. Moreover, they are used to save, update and secure the private information of users by using Cloud Storage such as iCloud, Dropbox and Google Drive. This study presents and adjusts the Technology Acceptance Model (TAM) specifically, perceived ease of use, usefulness, attitude toward usage and behavioral intention. Additionally, the study used Cornbach Alpha Correlation and Regression analysis in public universities, particularly in the University of Sulaimani. The study aims to recognize the major elements that have impact on using cloud storage and to what extent the user depends on electronic devices in the academic field and to identify the factors and crucial effect on the users to use electronic device easily, improve their capability and attract to use the specific technology. The results of this study confirmed that some TAM constructs direct and indirect effect on university academics, employees and students' behavioral intention to use cloud storage (Dropbox, iCloud and Google drive). However, the results regression analysis shows whenever users used the cloud storage easily perceived usefulness decreased the performance of job consequently. On the other hand, it went up the desirability to use the specific technology and own conscious scheme to execute for future.
\end{abstract}

Keywords: Cloud Computing, Cloud Storage, Smartphones, Technology Acceptance Model

\section{Introduction}

In recent years, computing has been mutated in a manner to consist of services delivered in a way similar to the traditional services as electricity, gas and water. The success of the new computing services depends on the user acceptance as it causes remarkable changes on people's lives. Users can access to these services based on their requirements regardless of the way they are hosted or delivered. The increasing need of users to such services makes them more expensive and time consuming, adopting a new technology like the cloud computing which plays an essential role in reducing the processing cost while improving the reliability, flexibility, availability and processing throughput (Choudhary and Vithayathil, 2013; Dwivedi and Mustafee, 2010; Oliveira et al., 2014).
The most recent computing innovation is the Cloud Computing and the term has been vital in the world of information technology (Ercan, 2010; Goscinski and Brock, 2010; Khurma et al., 2018). It can be defined in different ways and according to the National Institute of Standards and Technology (NIST), the cloud computing is "a model for enabling ubiquitous, convenient, ondemand network access to a shared pool of configurable computing resources (e.g., networks, server, storage, applications and services) that can be rapidly provisioned and released with minimal management effort or service provider interaction" (Mell and Grance, 2011). Moreover, it is referred to the using of applications as services, the hardware and the software to provide these services; where individuals can use them without thinking of hardware architecture and infrastructure 
(Armbrust et al., 2010; Marston et al., 2011; Shah, 2017; Tograph and Morgens, 2008). In term of classification, the cloud computing has three main approaches known as cloud delivery: Infrastructure as a Service (IaaS), Platform as a Service (PaaS) and Software as a Service (SaaS) (Goscinski and Brock, 2010; Low et al., 2011).

Several studies investigated that the innovation of cloud computing has been tested and used in different computational levels and systems which include business industries, healthcare, education, e-commerce, IT manufacturing and end users (Harfoushi et al., 2016; Hasan et al., 2015; Hayder et al., 2015; Mohamed et al., 2018). A survey conducted by Pew Research center stated that the cloud computing will be the more prevailing data hosting service for the end-users than the usual desktop computing where the data is moving to online storage systems such as iCloud, Google Drive, Dropbox and SkyDrive (Anderson and Rainie, 2010; 2011; Udoh, 2010).

Cloud computing is a coalescence of many computing fields and has gained a great popularity during the past few years. It provides computing, storage, services and applications over the internet. The cloud computing as a storage service can retain huge amounts of files to be shared among large numbers of users and each user can be accessed at anytime from anywhere, via personal computers and portable devices. Thus, Cloud Computing for Mobile (CCM) world came to the light in order to use cloud computing techniques for storage and processing of data on mobile devices. As a definition, MCC represents an infrastructure of various mobile devices (smartphones, tablets and laptops) that are connected to the internet via wireless networks. The main feature of the MCC provides users with data storage services an access to the cloud by which they can backup, revise, access, or share files over their own mobile devices (Arpaci, 2016).

Several studies present different benefits for the mobile cloud computing in lowering the cost of infrastructure and accessing the data (Zhang, 2012). Unfortunately, until now, it is not clear what are the benefits of adopting the mobile cloud computing and the several challenges that need to be solved. Many researchers have attempted to identify the factors that influence the adoption of the cloud computing. Buyya et al. (2009) stated that the cloud computing uses a third party service where the potential risk such as privacy and security, trusting the service provider are essential for ensuring a successful adoption. Mobile device ownership has recently experienced substantial growth and thus, the user acceptance of mobile cloud services has emerged as a significant research domain.

The main contribution of this study is to survey the adopting and understanding of key factors of the users' attitude and intentions of using mobile cloud storage services, in order to store and manage their own files and how to take advantage of this technology. TAM model has been carried out in this study to identify and understand the major factors influence accepting the cloud computing, its services and applications at the University of Sulaimani in Kurdistan, Iraq. It is considered as one of the most frequently used model for describing and explaining the users' acceptance and intentions to use any information systems.

The findings of the study will increase awareness about the extent of adoption the use of cloud storage amongst universities as well as the factors that effect on it. As a result, regulatory authorities in universities might use the results to encourage students, academics and non-academic staff to use cloud storage and give them an idea about helping them in their life. Moreover, regulatory authorities should be more careful with respect to the reasons for the poor using smartphones in an attempt to improve the attracting users, where this study illuminate the factors that causes this problem.

\section{Literature Review}

\section{The Concept of Cloud Computing}

Various efforts were made to investigate an adequate definition for the cloud computing since it has been introduced. For instance, Hayes (2008) clarify as on-demand computing, software as service or the internet as a platform. Hence, this seems to be a general definition and doesn't cover the comprehensive technical view of the cloud computing. Armbrust et al. (2009) and Shafiq et al. (2015) povides more descriptive definition for this technology as the applications that deliver services through the internet, where the hardware and the software in the data center provide these services. Rimal et al. (2009) promoting a comprehensive taxonomy for defining the cloud computing architecture in order to find out the technical strength and challenges in the current cloud systems based on the main idea of distributed systems for huge data processing. Noticeably, these definitions showed that the cloud computing helps in adopting IT services without taking into account the required infrastructure to run these services.

The widely known technical terms that are related to the cloud computing are Software as a Service (SaaS) which is the delivery of applications to users as a rental through the internet based infrastructure in different locations released by Salesforce.com Customer Resource Management (CRM), Google Apps, Oracle Siebel on Demand and Microsoft BPOS. While the Mobile SaaS would then involve mobile applications or services that run on local and context-aware mobile devices (Dihal et al., 2013). The Platform as a Service (PaaS) represents the clouds where the delivery of the services and the access to computers, databases and storage 
functions are done via a virtualized platform released by Salesforce.com, Microsoft Azure and Google App Engine. The end users can deploy the mobile cloud infrastructure and application without any control or management (Zadeh, 2014). The Infrastructure as a Service (IaaS) represents the delivery of computer infrastructure as a service. End users can install and run different software and have control over operating systems, storage and installed applications. The service provider is the owner of the equipment and is responsible for the housing, operation and maintenance. Examples of IaaS include Amazon Elastic Compute Cloud (EC2), Joyent, Rackspace and IBM Computing on Demand (Al Ladan, 2016).

Generally speaking, cloud computing opens the doors for the convergence of IT efficiency, business agility and economies of scales (Kim, 2009; Marston et al., 2011). Furthermore, this technology increases the optimization of resources and simplifies the collaboration DuranLimon et al. (2011; Park and Ryoo, 2013; Stantchev, 2009). However, the cloud applications face a number of challenges and present feasible problems as mentioned in (Colomo Palacios et al., 2014; Rebollo et al., 2012; Stantchev and Malek, 2011) the cloud technology creates risks in the computing industry related to the corporate governance issues, managing of services and their availability Stantchev and Stantcheva, 2013).

\section{Prior Research on Cloud Computing Adoption}

Because of the evolution of cloud computing over the past few years, it is necessary to study the diverse issues confronted from different perspective. The earlier studies took place in an equally urgent need to understand the business related issues regarding the cloud computing and its advantages. In addition to the benefits of energy saving, large amount of storage suitable for relatively small budgets, using IT without upfront investment, increasing the speed of markets by reducing the cost of operational expenses. In addition, it provides synchronized and continual access to the stored data through mobile devices (Blue and Tirotta, 2011). Nevertheless all these advantages and benefits of the cloud, this promising model still faces several challenges. Firstly, ensuring the security and the privacy of the provided service in the IT environment is equal to those in home (Brohi et al., 2014; Ion et al., 2011). Secondly, the reluctance of adopting the cloud raises concerns penetrating the physical location of the data center and the applied data management law. Thirdly, the required interoperability and portability that allow the users move between the providers. Finally, the Service Level Agreement (SLA) measures the quality of the service in order to increase the trust of the provider (Aloud and Ibrahim, 2018; Alotaibi, 2014; Dillon et al., 2010).
The reviewed studies focus on the adoption and use of cloud computing services. Alternatively, the major functionality of mobile cloud computing is to provide enhanced user experiences in terms of computation time, battery life, communication, services and mobile device resource enhancement (Al Ladan, 2016). Therefore, the mobile cloud computing should be able to provide an environment where users can use the storage services regardless of time and space as well as enjoy the numerous functions and capacity. Previous research showed that the usefulness is a key factor which affects the decision to start using the service. In addition, researches focus on how usefulness and technology acceptance model are related to show that usefulness influences intention to use cloud storage service (Jun et al., 2014). Behrend et al. (2011) showed that the ease of use particularly would affect students' intentions for future use where the students who finish their work in a practical way are more likely to recognize the cloud computing as an effective service compared with the negative effect on the perceived usefulness of the students who have apprehension from new technologies. Liu and Dong (2012) suggesting a handson training to help those students become more familiar with these new technologies.

\section{Cloud Storage Technology Acceptance Model (Tam) In Mobile Devices}

Cloud computing in mobile platforms has gained enormous popularity and rapidly increasing part in today's computing era due to the rapid development of mobile devices such as, smartphone, PDA and laptops along with the advent of mobile computing, networking and security technologies. These devices act as a cloud and provide access to local or internet based cloud services to other mobile devices and these devices are based on the functions of cluster applications, grid techniques and distributed file systems. Among others, mobile cloud storage services are the most closely related to end users where many applications support games, image processing, video processing, e-commerce and online social network services.

Cloud storage can be understood simply as storage in cloud computing and can also be considered as a cloud computing system equipped with large capacity storage. The architecture of the cloud storage system mainly includes storage layer, basic management layer, application interface layer and access layer. Cloud storage in the smartphone companies such as Apple, Dropbox, Microsoft and others offers several advantages likewise (Drago et al., 2012; Pocatilu et al., 2013) Solution for disaster recovery and data backup centralized data management, data storage costs saving, virtualized storage resources, collaborative working and 
user shared resources, scalability, business flexibility, synchronization over different devices.

The present study proposes a research framework based on the Technology Acceptance Model (TAM), it is rated to be one of the most commonly established theories of technology adoption and it has been pretended to be highly predictive of the adoption of various IT systems. The Technology Acceptance Model (TAM) was developed by Davis and Bagozzi (1989). Generally speaking, TAM identifies the users' intention to accept or reject a special technology by examining the users' behavioral attitude based on a series of tradeoffs between the perceived benefits of the system to the user and the complexity of learning or using the system (Davis and Bagozzi, 1989; Marjan et al., 2016).

TAM model posits that usefulness and ease of use are the key factors in determining user attitude towards adopting a new technology. It consists of (Malhotra and Galletta, 1999): (1) External Variables (EV) determines the factors that affect Perceived Usefulness (PU), Perceived Ease of Use (PEU) and Attitude toward Using. (2) Perceived Usefulness (PU) defined as the belief that using the particular technology will improve the users' action. (3) Perceived Ease of Use (PEU) defined as the belief that using the particular technology will be simple. (4) Attitudes towards use (A)which is defined as the users' desirability to use the particular technology. (5) Behavioral Intention (BI) is forecasted by attitude towards use (A) combined with perceived usefulness (PU). The effect of external variables was theorized to be mediated by $\mathrm{PU}$ and PEOU (Venkatesh and Bala, 2008).
The main goal of the study is to explore the extent to which users at the University of Sulaimani in Kurdistan Iraq would accept cloud storage services in smartphones.

\section{Hypotheses In Relation To Tam Variables}

This study provides research models and hypotheses based on theoretical assumptions. Researches on technology acceptance have been conducted with emphasis on user-centered psychological variables until recently. Now, researchers are also examining acceptance factors, including various attributes of information technology products. TAM was used as a baseline to verify the aims of the study. Therefore, the relationships between perceived ease of use, perceived usefulness, attitude toward using and behavioral intention are hypothesized as the following (Fig. 1):

H1: The perceived usefulness (PU) of cloud storage services has a positive influence on the attitude towards (ATU) cloud storage services.

$\mathrm{H} 2$ : The perceived ease of use (PEOU) of cloud storage services has a positive influence on the attitude towards (ATU) cloud storage services.

H3: The Perceived Ease Of Use (PEOU) of cloud storage services has a positive influence on the Perceived Usefulness (PU) of cloud storage services.

H4: The perceived usefulness (PU) of cloud storage services has a positive influence on the Behavioral Intention (BIU) to use cloud storage services.

H5: The Attitude Towards (ATU) adopting cloud storage services has a positive influence on the Behavioral Intention (BIU) to use cloud storage services.

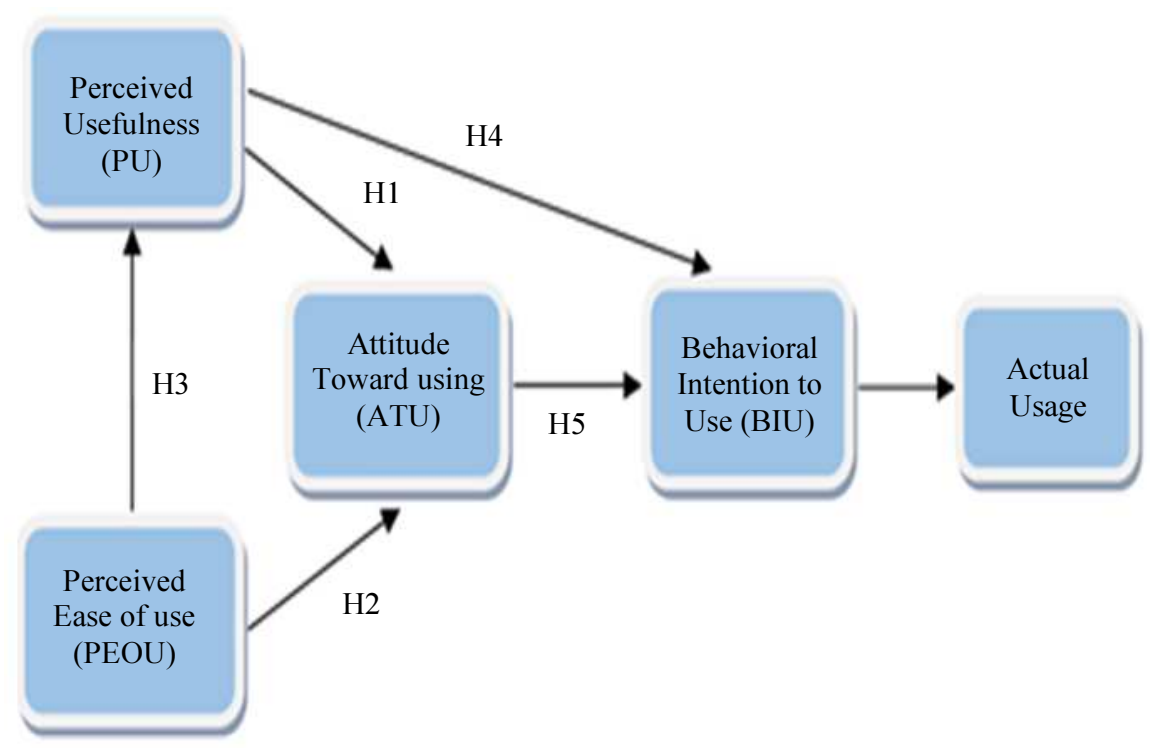

Fig. 1: The study hypotheses 


\section{Participants and Sampling Technique}

The participants in this study were (10) colleges members from different colleges and different departments who participated in the online survey and hardcopy survey. All participants in this study were academics, employees and students working for University of Sulaimani, who fit well with the aim and context of this study. The sampling technique used in the present study is exploration of technology acceptance. Further, the technique is used to ensure a better response rate in a short amount of time. Finally, it is against University of Sulaimani privacy policies to obtain academics' contacts and email addresses from the college or its departments. Hence, suitability sampling was the ideal technique for the purpose of this study.

\section{Instrumentation (Equipment)}

The research instrument consists of two main sections. The first section incorporates a nominal scale to identify respondents' demographic information. The second section uses 5-point Likert response scale where 1: Strongly disagree, 4: Partly disagree, 3: Moderately, 2: Partly agree and 1: Strongly agree. This section includes TAM concepts.

\section{Demographic Characteristics}

This part of the questioner identifies respondents' basic demographic characteristics. It contains (4) objects such as age, gender, occupation and certification, as shown in Table 2.

\section{Measuring TAM Constructs}

The second section of the survey Table 1, as discussed in the questionnaire design above, measures TAM constructs used in this study. As shown in Table 1, there are (23) objects measured in accordance with the current study's research model. The measured items include perceived ease of use (8 objects), perceived usefulness ( 7 objects), attitude toward usage (4 objects) and behavioral intention to use (4 objects).

\section{Data Collection}

The questionnaire was conducted at the beginning of academic year 2016-2017. The survey was distributed online by emailing and hardcopy a convenient sampling of (571) student, academic and non-academic staff. At this time, (571) questionnaires were distributed, (462) responses were recorded $(80.91 \%)$. Of that, only (427) responses yielded valid responses that were used for analysis. The overall response rate was $(74.78 \%)$.

Table 1: Questionnaire- Section 1

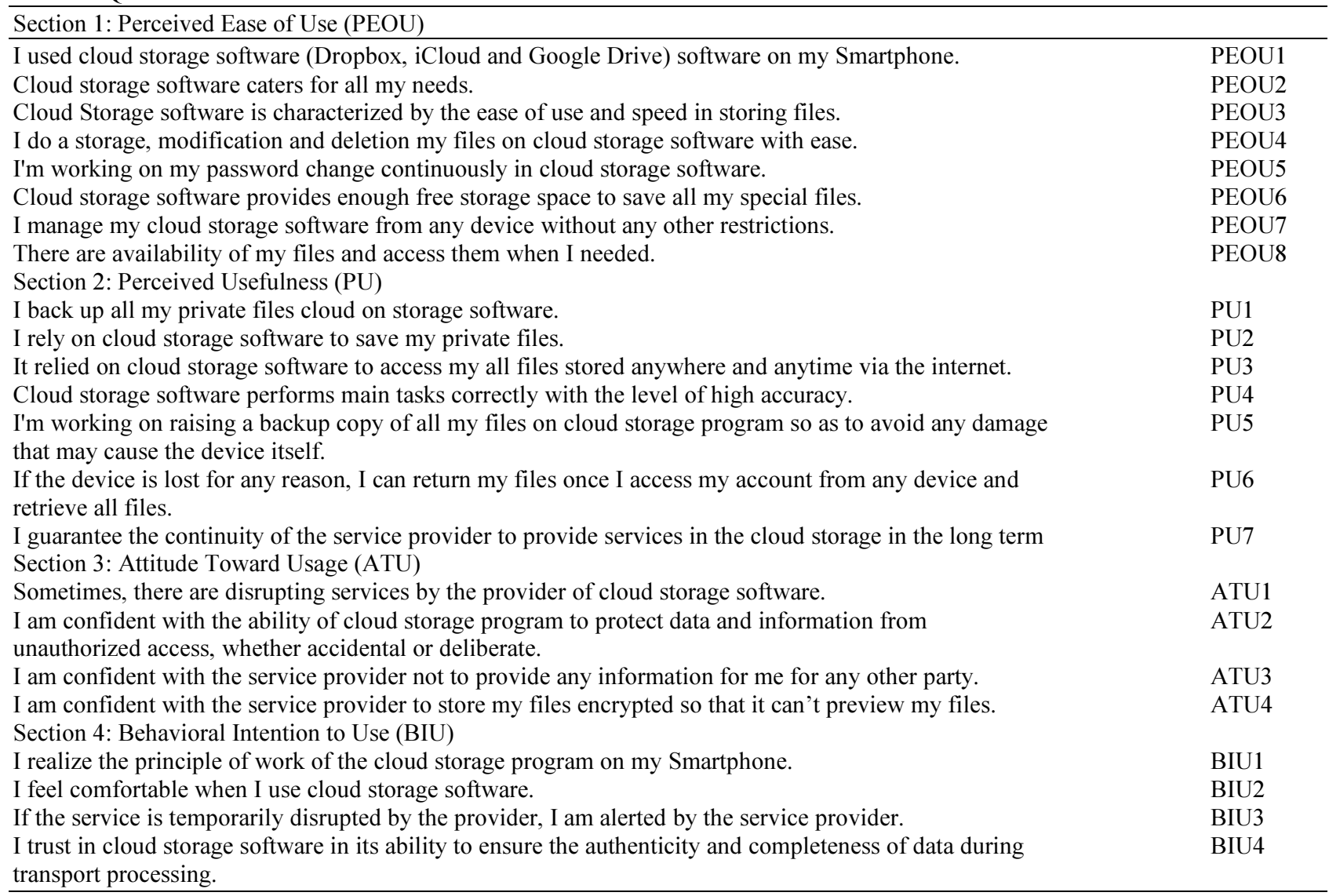




\section{Data Analysis and Results}

\section{Demographics}

The data analysis is utilized in tow steps, the first step comprises the measurement analysis and the second step includes the correlation and regression analysis. In this study, the reliability assessment was done using Statistical Package for Social Sciences (SPSS) version 23. The participants were almost equal in terms of gender, with (54\%) males and $(46 \%)$ females. The majority of participants were (51\%) between 21 and 30 years, with (26\%) from 31 to 40 and (13\%) below 20, with a low minority $(10 \%)$ above 40 years. The highest point of certificate participants was secondary school with (52\%), each of Master, Bachelor, PhD participants was (18\%), $(16 \%),(10 \%)$ respectively, whereas the lowest point was diploma with $(5 \%)$. The largest ratio participated students which were $(45 \%)$, the instructors witnessed the second one was $(30 \%)$ and however the last participant was employees which were $(25 \%)$. The rest of the figures and information are presented in Table 2.

\section{Validity and Reliability}

In addition to the steps mentioned earlier to assess the validity and reliability of the study tools, a further test was executed. Reliability concerns to measure many inner of variables in regularity, Cronbach Alpha is generally utilized in order to evaluate it and the value should exceeds (0.70) for each variable (Saleh and Steve, 2014). Table 3 shows cronbach Alpha regards to the test of reliability of a skill.

Table 2: Questionnaire-section 2

\begin{tabular}{llcl}
\hline Section I: Demographic Characteristics Information & \\
\hline Variables & Characteristics & Frequency & \% \\
\hline Gender & Male & 229 & $54 \%$ \\
& Female & 198 & $46 \%$ \\
& Below 20 years & 55 & $13 \%$ \\
& Between 21-30 & 216 & $51 \%$ \\
& Between 31-40 & 112 & $26 \%$ \\
Certificate & Above 40 Years & 44 & $10 \%$ \\
& Secondary School & 193 & $52 \%$ \\
& Diploma & 22 & $5 \%$ \\
& Bachelors & 79 & $16 \%$ \\
& Master & 85 & $18 \%$ \\
& PhD & 48 & $10 \%$ \\
& Instructor & 133 & $30 \%$ \\
& Employee & 112 & $25 \%$ \\
& Student & 182 & $45 \%$ \\
\hline
\end{tabular}

Table 3: Instruments reliability cornbach alpha

\begin{tabular}{lcl}
\hline Scale & $\begin{array}{l}\text { Number } \\
\text { of objects }\end{array}$ & $\begin{array}{l}\text { Cronbach } \\
\text { alpha }\end{array}$ \\
\hline Perceived Ease of Use (PEOU) & 8 & 0.882 \\
Perceived Usefulness (PU) & 7 & 0.858 \\
Attitude Toward Usage (ATU) & 4 & 0.766 \\
Behavioral Intention to Use (BIU) & 4 & 0.797 \\
Overall Reliability & 23 & 0.954 \\
\hline
\end{tabular}

\section{Hypotheses Testing For All Participants}

The In this section we used the sample size as a whole to test the research hypotheses. Hypotheses on the relationship between TAM original variables are presented first.

Table 4 illustrates information about the correlation analysis consequence between dependent and independent variable, the correlation coefficient between perceived usefulness (PU) and attitude towards (ATU) of a cloud storage services is $(r=0.967, p>0.05)$. It can be witnessed that there is a significant positive relationship between Perceived Usefulness (PU) and attitude towards (ATU). Therefore, $\mathrm{H} 1$ is supported.

Table 5 provides information about the correlation analysis consequence between dependent and independent variables, the correlation coefficient between Perceived Ease Of Use (PEOU) and Attitude Towards (ATU) of a cloud storage services is $(r=0.970, p>0.05)$. It can be witnessed that there is a significant positive relationship between Perceived Ease Of Use (PEOU) and the Attitude Towards (ATU). Therefore, H2 is supported.

Table 6 explains information about the correlation analysis consequence between dependent and independent variables, the correlation coefficient between Perceived Ease Of Use (PEOU) and Perceived Usefulness (PU) of a cloud storage services is $(r=0.989, p>0.05)$. It can be witnessed that there is a significant positive relationship between Perceived Ease Of Use (PEOU) and Perceived Usefulness (PU). Therefore, H3 is supported.

Table 4: PU and ATU correlations

\begin{tabular}{lll}
\hline Correlations & & \\
\hline Factors & Perceived usefulness (PU) & \\
\hline ATU & r-value & $0.967^{* *}$ \\
& p-value & 0.000 \\
& $\mathrm{~N}$ & 427 \\
\hline
\end{tabular}

PU: Perceived Usefulness

ATU: Attitude Towards

Table 5: PEOU and ATU correlations

Correlations

\begin{tabular}{lll}
\hline Factors & PEOU & \\
\hline ATU & r-value & $.970^{* *}$ \\
& p-value & 0.000 \\
& $\mathrm{~N}$ & 427 \\
\hline
\end{tabular}

PEOU: Perceived Ease of Use

ATU: Attitude Towards

Table 6: PEOU and PU correlations

\begin{tabular}{lll}
\hline Correlations & & \\
\hdashline Factors & PEOU & \\
\hline PU & r-value & $0.989^{* *}$ \\
& p-value & 0.000 \\
& $\mathrm{~N}$ & 427 \\
\hline
\end{tabular}

PEOU: Perceived Ease of Use

PU: Perceived Usefulness 
Table 7 illuminates information about the correlation analysis consequence between dependent and independent variables, the correlation coefficient between Perceived Usefulness (PU) and Behavioral Intention (BIU) of a cloud storage services is $(r=$ $0.983, p>0.05)$. It can be witnessed that there is a significant positive relationship between Perceived Usefulness (PU) and Behavioral Intention (BIU). Therefore, H4 is supported.

Table 8 illustrates information about the correlation analysis consequence between dependent and independent variables, the correlation coefficient between Attitude Towards (ATU) and behavioral intention (BIU) of a cloud storage services is $(r=0.968, p>0.05)$. It can be witnessed that there is a significant positive relationship between the Attitude Towards (ATU) and the Behavioral Intention (BIU). Therefore, H5 is supported.

The relative order of preference of the predictive factors of user's attitude towards using cloud storage based on the beta values given in Table 9 can be synopsized as follows: Perceived Usefulness (PU) and attitude towards (ATU) $(\mathrm{B}=0.553)$ and perceived ease of use (PEOU) and attitude towards (ATU) $(\mathrm{B}=0.269)$, These factors are statistically significant at the level of significance $5 \%$ as the $p$ value corresponding for two factors are below (0.05). Thus, H1, H2 are accepted. The overall model was statistically significant $(\mathrm{R} 2=0.943$, $\mathrm{p}<0.01)$. The results of the regression analysis were presented in Table 10. The R-squared value of 0.943 implied that the 2-predictor variables explained about $94.3 \%$ using of the cloud storage acceptance.

Table 7: PU and BIU Correlations Correlations

\begin{tabular}{lll} 
Factors & PU & \\
\hline BIU & r-value & $0.983 * *$ \\
& p-value & 0.000 \\
& N & 427 \\
\hline
\end{tabular}

PU: Perceived Usefulness

BIU: Behavioral Intention

Table 8: ATU and BIU Correlations Correlations

\begin{tabular}{lll} 
Factors & ATU & \\
\hline BIU & r-value & $0.968^{* *}$ \\
& p-value & 0.000 \\
& $\mathrm{~N}$ & 427 \\
\hline
\end{tabular}

ATU: Attitude Towards

BIU: Behavioral Intention

Table 9: Result of Multiple Regression Coefficients $^{\mathrm{a}}$

\begin{tabular}{|c|c|c|c|c|c|}
\hline \multirow[b]{2}{*}{ Model } & \multicolumn{5}{|c|}{ Unstandardized Coefficients } \\
\hline & $\mathrm{B}$ & Std. Error & $\begin{array}{l}\text { Standardized Coefficients } \\
\text { Beta }\end{array}$ & $\mathrm{T}$ & Sig. \\
\hline (Constant) & 0.207 & 0.033 & & 6.202 & 0.000 \\
\hline PU & 0.349 & 0.075 & 0.370 & 4.674 & 0.000 \\
\hline POEU & 0.570 & 0.075 & 0.604 & 7.623 & 0.000 \\
\hline
\end{tabular}

a. Dependent Variable: ATU

Table 10: Model summary for cloud storage (Y1) model

Model Summary ${ }^{\mathrm{b}}$

\begin{tabular}{|c|c|c|c|c|c|c|c|c|c|c|}
\hline \multirow[b]{2}{*}{ Model } & \multirow[b]{2}{*}{$\mathrm{R}$} & \multirow[b]{2}{*}{ R Square } & \multirow[b]{2}{*}{$\begin{array}{l}\text { Adjusted } \\
\text { R Square }\end{array}$} & \multirow[b]{2}{*}{$\begin{array}{l}\text { Std. Error of } \\
\text { the Estimate }\end{array}$} & \multirow[b]{2}{*}{$\begin{array}{l}\text { R Square } \\
\text { Change }\end{array}$} & \multicolumn{5}{|c|}{ Change Statistics } \\
\hline & & & & & & F Change & $\mathrm{df1}$ & $\mathrm{df} 2$ & $\begin{array}{l}\text { Sig. F } \\
\text { Change }\end{array}$ & $\begin{array}{l}\text { Durbin- } \\
\text { Watson }\end{array}$ \\
\hline 1 & $0.971 \mathrm{a}$ & 0.943 & 0.943 & 0.284 & 0.943 & 3538.149 & 2 & 424 & 0.000 & 0.476 \\
\hline
\end{tabular}

a. Predictors: (Constant), Perceived Usefulness (PU), Perceived Ease of Use (PEOU)

b. Dependent Variable: Attitude Towards (ATU)

Table 11: Result of multiple regression

Coefficients $^{\mathrm{a}}$

\begin{tabular}{|c|c|c|c|c|c|c|}
\hline & \multirow[b]{2}{*}{ Model } & \multicolumn{5}{|c|}{ Unstandardized Coefficients } \\
\hline & & B & Std. Error & $\begin{array}{l}\text { Standardized Coefficients } \\
\text { Beta }\end{array}$ & $\mathrm{T}$ & Sig. \\
\hline 2 & $\begin{array}{l}\text { (Constant) } \\
\text { PEOU }\end{array}$ & $\begin{array}{l}-0.010 \\
0.991\end{array}$ & $\begin{array}{l}0.022 \\
0.007\end{array}$ & 0.989 & $\begin{array}{l}-0.458 \\
139.874\end{array}$ & $\begin{array}{l}0.647 \\
0.000\end{array}$ \\
\hline
\end{tabular}

a. Dependent Variable: PU 
The relative order of preference of the predictive factors of user's perceived usefulness utilizing cloud storage based on the beta value given in Table 11 can be summarized as follows: Perceived Ease Of Use (PEOU) and Perceived Usefulness (PU) $(\mathrm{B}=0.989)$. These independent factors are statistically significant at the level of significance $5 \%$ as the $p$ value corresponding for the factor is above $(0.05)$. Thus, $\mathrm{H} 3$ is rejected. The overall model was statistically significant $(\mathrm{R} 2=0.979$, $\mathrm{p}<0.01)$. The results of the regression analysis were presented in Table 12. The R-squared value of 0.979 implied that the 1-predictor variables explained about $97.9 \%$ using of the cloud storage reject.
The relative order of preference of the predictive factors of user's intention towards using cloud storage based on the beta values given in Table 13 can be synopsized as follows: Perceived Usefulness (PU) and behavioral intention (BIU) $(\mathrm{B}=0.739)$ and Attitude Towards (ATU) and behavioral intention (BIU) $(\mathrm{B}=$ 0.253 ). These factors are statistically significant at $5 \%$ level of significance as the $p$ value corresponding for four factors are below (0.05). Thus, $\mathrm{H} 4$ and $\mathrm{H} 5$, are accepted. The overall model was statistically significant $(\mathrm{R} 2=$ $0.971, p<0.01)$. The results of the regression analysis were presented in Table 14. The R-squared value of 0.971 implied that the 2-predictor variables explained about $97.1 \%$ using of the cloud storage acceptance.

Table 12: Model Summary for Cloud Storage (Y2) Model Model Summary ${ }^{\mathrm{b}}$

Change Statistics

\begin{tabular}{lllllllllll} 
Model & R & R Square & $\begin{array}{l}\text { Adjusted } \\
\text { R Square }\end{array}$ & $\begin{array}{l}\text { Std. error of } \\
\text { the estimate }\end{array}$ & $\begin{array}{l}\text { R square } \\
\text { change }\end{array}$ & F Change & df1 & df2 & $\begin{array}{l}\text { Sig. F } \\
\text { Change }\end{array}$ & $\begin{array}{l}\text { Durbin- } \\
\text { Watson }\end{array}$ \\
\hline 2 & $0.989 \mathrm{a}$ & 0.979 & 0.979 & 0.184 & 0.979 & 19564.757 & 1 & 425 & 0.000 & $0.989 \mathrm{a}$ \\
\hline
\end{tabular}

a. Predictors: (Constant), Perceived Ease of Use (PEOU)

b. Dependent Variable: Perceived Usefulness (PU)

Table 13: Result of multiple regressions Coefficients $^{\mathrm{a}}$

\begin{tabular}{|c|c|c|c|c|c|c|}
\hline & & \multicolumn{5}{|c|}{ Unstandardized Coefficients } \\
\hline \multicolumn{2}{|c|}{ Model } & $\mathrm{B}$ & Std. Error & $\begin{array}{l}\text { Standardized coefficients } \\
\text { Beta }\end{array}$ & $\mathrm{T}$ & Sig. \\
\hline \multirow[t]{3}{*}{3} & (Constant) & 0.051 & 0.026 & & 1.968 & 0.050 \\
\hline & PU & 0.731 & 0.032 & 0.739 & 22.741 & 0.000 \\
\hline & ATU & 0.265 & 0.034 & 0.253 & 7.769 & 0.000 \\
\hline
\end{tabular}

a. Dependent Variable: BIU

Table 14: Model summary for cloud storage (Y3)

Model Summary ${ }^{\mathrm{b}}$

\begin{tabular}{|c|c|c|c|c|c|c|c|c|}
\hline \multirow[b]{2}{*}{$\mathrm{R}$} & \multirow[b]{2}{*}{ R Square } & \multirow{2}{*}{$\begin{array}{l}\text { Adjusted } \\
\text { R Square }\end{array}$} & \multirow{2}{*}{$\begin{array}{l}\text { Std. Error of } \\
\text { the Estimate }\end{array}$} & \multicolumn{5}{|l|}{ Change Statistics } \\
\hline & & & & R Square change & F Change & $\mathrm{df1}$ & $\mathrm{df} 2$ & Sig. F change \\
\hline $0.985 \mathrm{a}$ & 0.971 & 0.971 & 0.212 & 0.971 & 7151.023 & 2 & 424 & 0.000 \\
\hline
\end{tabular}

a. Predictors: (Constant), Attitude Towards (ATU), Perceived Usefulness (PU)

b. Dependent Variable: Behavioral Intention (BIU)

Table 15: Hypothesis summary hypothesis statement result

\begin{tabular}{|c|c|c|c|}
\hline \multirow[b]{2}{*}{ Hypothesis } & \multirow[b]{2}{*}{ Statement } & \multicolumn{2}{|l|}{ Result } \\
\hline & & Correlation & Regression analysis \\
\hline H1 & $\begin{array}{l}\text { The perceived usefulness (PU) of cloud storage services has a } \\
\text { positive influence on the attitude towards (ATU) cloud storage services. }\end{array}$ & Supported & Supported \\
\hline $\mathrm{H} 2$ & $\begin{array}{l}\text { The perceived ease of use (PEOU) of cloud storage services has a } \\
\text { positive influence on the attitude towards (ATU) cloud storage services. }\end{array}$ & Supported & Supported \\
\hline H3: & $\begin{array}{l}\text { The perceived ease of use (PEOU) of cloud storage services has a } \\
\text { positive influence on the perceived usefulness (PU) of cloud storage services. }\end{array}$ & Supported & Unsupported \\
\hline $\mathrm{H} 4$ & $\begin{array}{l}\text { The perceived usefulness (PU) of cloud storage services has a positive } \\
\text { influence on the behavioral intention (BIU) to use cloud storage services. }\end{array}$ & Supported & Supported \\
\hline H5 & $\begin{array}{l}\text { The attitude towards (ATU) adopting cloud storage services has a positive } \\
\text { influence on the behavioral intention (BIU) to use cloud storage services. }\end{array}$ & Supported & Supported \\
\hline
\end{tabular}


The study has tested five hypotheses using correlation and regression analysis and it is observed from Table 15, the consequences are appeared and the whole hypotheses in correlation were positive significant. Further, the study designates that when users' perceived ease of use increases, the perceived usefulness increment consequently. As expected, when academics perceived cloud storage (Dropbox, iCloud and Google drive) as easy to use, they developed a positive attitude towards utilizing it. Similarly, the perceived usefulness rose the degree of positivity toward usage, which subsequently affected the behavioral intention to use. However, the results regression analysis shows whenever users used the cloud storage easily perceived usefulness decreased the performance of job consequently. On the other hand, it went up the desirability to use the specific technology and own conscious scheme to execute for future.

\section{Conclusion}

The goal of this study was to recognize the factors that affect the adoption of cloud storage at the Sulaimani University in Kurdistan Regional Government-Iraqi. The TA models suggest that perceived ease of use has a significant influence on perceived usefulness, behavior attitude, intention and actual use. The result of this study shows that perceived ease of use, perceived usefulness, attitude, behavioral intention are the important determinants of extend the users to rely on cloud storage. The outcome of the study confirmed that some TAM constructs had a direct and indirect effect on university academics, employees and students' behavioral intention to use cloud storage (Dropbox, iCloud and Google drive). For that reason, there is potential for practical application in the development and management of cloud computing in university. The Technology acceptance model is common models for grasping the acceptance of Information systems. The TA model has been largely used by researchers in international studies related to information systems.

It has also been adjusted and improved by researchers in several studies. Cloud computing is the inevitable product with the improvement of the internet and it also brings scientific applications to the internet. Cloud storage technology is the essential area to provide the security for data stored on cloud, easy to manage storage systems and modification, deletion, easy to sort and retrieve files in the cloud environment since the users of cloud technology are rising steeply.

\section{Research Limitations and Future Work}

As future work, we propose to extend our study with TAM from other locations and longer time intervals. This allows us to quantify long-term effects of design choices for users connected in various academic areas. Future studies could focus on general ICT adoption for teaching and learning.

\section{Acknowledgment}

The authors would like to thank the University of Sulaimaniyah for their support in writing this article.

\section{Author's Contributions}

All authors equally contributed in this work.

\section{Ethics}

This article is original and contains unpublished material. The authors confirm that are no conflict of interest involved.

\section{References}

Al Ladan, M.I., 2016. A review and classifications of mobile cloud computing security issues. Proceedings of the 11th International Conference on Cyber Warfare and Security, (CWS' 16), p: 214-214.

Alotaibi, M.B., 2014. Exploring users' attitudes and intentions toward the adoption of cloud computing in Saudi Arabia: An empirical investigation. J. Comput. Sci., 10: 2315-25.

DOI: $10.3844 /$ jcssp.2014.2315.2329

Aloud, H. and Y. Ibrahim, 2018. Factors influencing the citizen trust to adopt e-government services in Saudi Arabia. J. Theoretical Applied Inform. Technol., 96: 5015-5030.

Anderson, J.Q. and H. Rainie, 2010. The future of cloud computing. Pew Research Center.

Anderson, J.Q. and H. Rainie, 2011. The 2011 cloud trends and best practices report.

Armbrust, M., A. Fox, R. Griffith, A.D. Joseph and R. Katz et al., 2010. A view of cloud computing. Commun. ACM, 53: 50-58. DOI: $10.1145 / 1721654.1721672$

Armbrust, M., A. Fox, R. Griffnd Aith, A.D. Joseph and R.H. Katz et al., 2009. Above the clouds: A Berkeley view of cloud computing.

Arpaci, I., 2016. Understanding and predicting students' intention to use mobile cloud storage services. Comput. Human Behav., 58: 150-157.

DOI: $10.1016 /$ j.chb.2015.12.067

Behrend, T.S., E.N. Wiebe, J.E. London and E.C. Johnson, 2011. Cloud computing adoption and usage in community colleges. Behav. Inform. Technol., 30: 231-240. DOI: $10.1080 / 0144929 X .2010 .489118$

Blue, E. and R. Tirotta, 2011. The benefits and drawbacks of integrating cloud computing and interactive whiteboards in teacher preparation TechTrends, 55: 31-39. DOI: $10.1007 / \mathrm{s} 11528-011-0495-7$ 
Brohi, S., M. Bamiah, S. Chuprat and J. Ab Manan, 2014. Design and implementation of a privacy preserved off-premises cloud storage. J. Comput. Sci., 10: 210-223. DOI: 10.3844/jcssp.2014.210.223

Buyya, R., S. Pandey and C. Vecchiola, 2009. Cloud bus toolkit for market-oriented cloud computing. Proceedings of the IEEE 1st International Conference on Cloud Computing, Dec. 1-4, Springer, Germany, pp: 24-44.

DOI: $10.1007 / 978-3-642-10665-14$

Choudhary, V. and J. Vithayathil, $20 \overline{13}$. The impact of cloud computing: Should the IT department be organized as a cost center or a profit center? J. Manage. Inform. Syst., 30: 67-100.

DOI: 10.2753/MIS0742-1222300203

Colomo Palacios, R., C. Casado-Lumbreras, S. Misra and P. Soto-Acosta, 2014. Career abandonment intentions among software workers. Human Factors Ergonom. Manufact. Service Indust., 24: 641-655. DOI: $10.1002 / \mathrm{hfm} .20509$

Davis, F. and R. Bagozzi, 1989. User acceptance of computer technology: A comparison of two theoretical models. Manage. Sci., 35: 903-1028. DOI: $10.1287 / \mathrm{mnsc} .35 .8 .982$

Dihal, S., H. Bouwman, M. de Reuver, M. Warnier and C. Carlsson, 2013. Mobile cloud computing: State of the art and outlook. Info, 15: 4-16. DOI: $10.1108 / 14636691311296174$

Dillon, T., C. Wu and E. Chang, 2010. Cloud computing: Issues and challenges. Proceedings of the 24th IEEE International Conference on Advanced Information Networking and Applications, Apr. 20-23, IEEE Xplore Press, Perth, WA, Australia, pp: 27-33. DOI: $10.1109 / A I N A .2010 .187$

Drago, I., M. Mellia, M. Munafo, A. Sperotto and R. Sadre et al., 2012. Inside dropbox: Understanding personal cloud storage services. Proceedings of the ACM Conference on Internet Measurement Conference, Nov. 14-16, ACM, Boston, Massachusetts, USA, pp: 481-494.

DOI: $10.1145 / 2398776.2398827$

Duran-Limon, H.A., M. Siller, G.S. Blair, A. Lopez and J.F. Lombera-Landa, 2011. Using lightweight virtual machines to achieve resource adaptation in middleware. IET Software, 5: 229-237.

DOI: 10.1049 /iet-sen.2009.0091

Dwivedi, Y.K. and N. Mustafee, 2010. It's unwritten in the Cloud: The technology enablers for realizing the promise of cloud computing. J. Enterprise Inform. Manage., 23: 673-679. DOI: $10.1108 / 17410391011088583$

Ercan, T., 2010. Effective use of cloud computing in educational institutions. Proc. Soc. Behav. Sci., 2: 938-942. DOI: 10.1016/j.sbspro.2010.03.130
Goscinski, A. and M. Brock, 2010. Toward dynamic and attribute based publication, discovery and selection for cloud computing. Future Generat. Comput. Syst., 26: 947-970. DOI: 10.1016/j.future.2010.03.009

Harfoushi, O., A.H. Akhorshaideh, N. Aqqa, M. Al Janini and R. Obiedat, 2016. Factors affecting the intention of adopting cloud computing in jordanian hospitals. Commun. Netw., 8: 67003-67003. DOI: $10.4236 / \mathrm{cn} .2016 .82010$

Hasan, L.M., L.A. Zgair, A.A. Ngotoye, H.N. Hussain and C. Najmuldeen, 2015. A review of the factors that influence the adoption of cloud computing by small and medium enterprises. Scholars J. Econom. Bus. Manage., 2: 842-848.

Hayder, S.H., B.H. Zainuddin and S.H. Ali, 2015. Factors influence the adoption of cloud computing: A comprehensive review. Int. J. Educ. Res., 3: 295-30.

Hayes, B., 2008. Cloud computing. Commun. ACM, 51: 9-11. DOI: $10.1145 / 1364782.1364786$

Ion, I., N. Sachdeva, P. Kumaraguru and S. Čapkun, 2011. Home is safer than the cloud!: Privacy concerns for consumer cloud storage. Proceedings of the 7th Symposium on Usable Privacy and Security, Jul. 20-22, ACM, Pittsburgh, Pennsylvania, pp: 13-13. DOI: $10.1145 / 2078827.2078845$

Jun, C.J., J.H. Lee and I.S. Jeon, 2014. Research about factor affecting the continuous use of cloud storage service: User factor, system factor, psychological switching cost factor. J. Society for e-Bus. Stud.

Khurma, R., H. Harahsheh and A. Sharieh, 2018. Task scheduling algorithm in cloud computing based on modified round robin algorithm. J. Theoretical Applied Inform. Technol., 96: 5869-5888.

Kim, W., 2009. Cloud computing: Status and prognosis. J. Object Technol., 8: 65-72.

Liu, K. and L.J. Dong, 2012. Research on cloud data storage technology and its architecture implementation. Proc. Eng., 29: 133-137.

DOI: $10.1016 /$ j.proeng.2011.12.682

Low, C., Y. Chen and M. Wu, 2011. Understanding the determinants of cloud computing adoption. Indust. Manage. Data Syst., 111: 1006-1023. DOI: $10.1108 / 02635571111161262$

Malhotra, Y. and D.F. Galletta, 1999. Extending the technology acceptance model to account for social influence: Theoretical bases and empirical validation. Proceedings of the 32nd Annual Hawaii International Conference on Systems Sciences, Jan. 5-8, IEEE Xplore Press, Maui, HI, USA, pp: 14-14. DOI: 10.1109/HICSS.1999.772658

Marjan. M.G, H. Ab Razak and A. Azam, 2016. Human factors' impact leveraging cloud based applications adoption. J. Inform. Syst. Res. Innovat. 
Marston, S., Z. Li, S. Bandyopadhyay, J. Zhang and A. Ghalsasi, 2011. Cloud computing-the business perspective. Dec. Support Syst., 51: 176-189. DOI: $10.1016 /$ j.dss.2010.12.006

Mell, P. and T, Grance, 2011. The NIST definition of cloud computing.

Mohamed, A., R. Jenal and S.A. Hanawi, 2018. The impact of e-commerce adoption for small and medium enterprise in developing country: A case study Uganda. J. Theoretical Applied Inform. Technol., 96: 6141-6149.

Oliveira, T., M. Thomas and M. Espadanal, 2014. Assessing the determinants of cloud computing adoption: An analysis of the manufacturing and services sectors. Inform. Manage., 51: 497-510. DOI: $10.1016 / \mathrm{j} . \mathrm{im} .2014 .03 .006$

Park, S.C. and S.Y. Ryoo, 2013. An empirical investigation of end-users' switching toward cloud computing: A two factor theory perspective. Comput. Human Behav., 29: 160-170.

DOI: 10.1016/j.chb.2012.07.032

Pocatilu, P., C. Boja and C. Ciurea, 2013. Syncing mobile applications with cloud storage services. Inform. Econ., 17: 96.

Rebollo, O., D. Mellado and E. Fern Undez-Medina, 2012. A systematic review of information security governance frameworks in the cloud computing environment. J. UCS, 18: 798-815.

Rimal, B.P., E. Choi and I. Lumb, 2009. A taxonomy and survey of cloud computing systems. Proceedings of the 5th International Joint Conference on INC, IMS and IDC, Aug. 25-27, IEEE Xplore Press, Seoul, South Korea, pp: 44-51. DOI: 10.1109/NCM.2009.218

Shafiq, A., M. Aslam, A. Ahmed and S. Islam, 2015. Prevention from malicious programs for handling security issues in mobile cloud computing. Sci. Int.

Shah, S., 2017. A mobile ad hoc cloud computing and networking infrastructure for automated video surveillance system. J. Comput. Sci., 13: 767-780. DOI: $10.3844 /$ jcssp.2017.767.780.
Saleh A. and D. Steve, 2014. Using the Technology Acceptance Model in Understanding Academics' Behavioural Intention to Use Learning Management Systems, (IJACSA) International Journal of Advanced Computer Science and Applications, Vol. 5, No. 1, pp. 150 .

Stantchev, V. and L. Stantcheva, 2013. Applying ITgovernance frameworks for SOA and cloud governance. Proceedings of the 4 th World Summit on the Knowledge Society Information Systems, Elearning and Knowledge Management Research, Sept. 21-23, Mykonos, Greece, pp: 278-398. DOI: $10.1007 / 978-3-642-35879-148$

Stantchev, V. and M. Malek, 2011. Addressing dependability throughout the SOA life cycle. IEEE Trans. Services Comput., 4: 85-95. DOI: $10.1109 /$ TSC.2010.15

Stantchev, V., 2009. Performance evaluation of cloud computing offerings. Proceedings of the 3rd International Conference on Advanced Engineering Computing and Applications in Sciences, Oct. 11-16, IEEE Xplore Press, Sliema, Malta, pp: 187-192. DOI: 10.1109/ADVCOMP.2009.36

Tograph, B. and Y.R. Morgens, 2008. Cloud computing. Commun. ACM, 51: 9-11. DOI: $10.1145 / 1364782.1364786$

Udoh, E.E., 2010. The adoption of grid computing technology by organizations: A quantitative study using technology acceptance model. ProQuest LLC. 789 East Eisenhower Parkway, PO Box 1346, Ann Arbor, MI 48106.

Venkatesh, V. and H. Bala, 2008. Technology acceptance model 3 and a research agenda on interventions. Dec. Sci., 39: 273-315. DOI: $10.1111 /$ j.1540-5915.2008.00192.x

Zadeh, M.H.K., 2014. Secure intelligent information management by using a framework of virtual phones based on cloud computation. Arabian J. Bus. Manage. Rev., 3: 173-183.

Zhang, L.J., 2012. Editorial: Big services era: Global trends of cloud computing and big data. IEEE Trans. Services Comput., 5: 467-468. DOI: $10.1109 /$ TSC.2012.36 